\title{
Retraction
}

\section{IKKa-mediated biogenesis of miR-196a through interaction with Drosha regulates the sensitivity of cancer cells to radiotherapy}

X Fang, J-H Jeong, X Long, S-J Park, D Wang, M Shuai, R Wei, C Li, S Li, S Zhang, MB Duran, K-W Lo, SW Tsao, R Glaser, $Z$ Luo, $X$ Feng, $Y$ Tian and J-L Luo

Cell Death and Differentiation (2017) 24, 1133; doi:10.1038/cdd.2016.106; published online 16 September 2016

Retraction to: Cell Death Differ 2016;23(9):1471-1482. doi:10.1038/cdd.2016.32

Following the identification of discrepancies between images and the data, and at the request of the authors, we are retracting the following paper: "IKKa -mediated biogenesis of miR-196a through interaction with Drosha regulates the sensitivity of cancer cells to radiotherapy" by Fang et al. Cell Death Differ 2016 Sep 1;23(9):1471-82. doi: 10.1038/cdd.2016.32. 